\title{
Fully Differential Universal Current-Mode Frequency Filters Based on Signal-Flow Graphs Method
}

\author{
L. Langhammer and J. Jerabek
}

\begin{abstract}
Two new circuits of 2nd order universal frequency filter designed using signal-flow graphs method are presented. Both filters were proposed in single-ended and fully-differential forms. Multiple-output current follower (MO-CF) and digitally adjustable current amplifier (DACA) used in proposal are described in the paper. The pole frequency and the quality factor of filters can be controlled by the current gain of digitally adjustable current amplifiers suitably placed in the circuit structure. The actual function of the proposed filters is verified using PSpice simulation. Simulation results of proposed filters are also included in this paper.
\end{abstract}

Keywords - Current amplifier, Current follower, Current mode, Frequency filter, Fully differential, Single ended

\section{INTRODUCTION}

There are multiple methods how to approach to design of frequency filters. One of the general filter-design method frequently used for the proposal of new filters is autonomous circuit design method described in [1-4]. An autonomous circuit is presented as a circuit of passive and active elements which possesses no excitation source and has no selected input or output terminal. Such a circuit is solely described by the characteristic equation. These autonomous circuits then serve as a default circuit to design various types of frequency filters [4]. We can also mention a method of synthetic immittance system which can be found for instance in [4-6]. Higher-order immittance synthetic elements consist of serial or parallel combinations of elementary D or E type dipoles. There are four synthetic elementary dipoles connections with immittance of higher order namely DP, DS, EP, ES [6]. Other known way how to propose frequency filters is using signal-flow graphs (SFGs) method described in papers such as [4], [7], [8]. For synthesis and analysis of electrical circuits Mason-Coates' (M-C) flow graphs are used. These graphs can be understood as diagrams representing mutual relations between nods and branches of the analyzed circuit. Using this method we can directly propose circuits of frequency filters in two steps. Firstly, a type of the transfer function is determined. Subsequently, the rules of M-C graphs are used to create a graph of the proposed circuit described by its transfer function. From this graph the circuit network can be easily made [7].

Manuscript received November 18, 2013 revised March 27, 2014.

L. Langhammer Faculty of Electrical Engineering and Communication, Brno University of Technology, Technicka 12, 61600 Brno, Czech Republic (e-mail: xlangh01@stud.feec.vutbr.cz)

J. Jerabek Faculty of Electrical Engineering and Telecommunication, Brno University of Technology, Technicka 12, 61600 Brno, Czech Republic (e-mail: jerabekj@feec.vutbr.cz)
Lately we can experience a trend of decreasing of supply voltage caused by reducing of the integrated circuit size. Growning requirements on circuit with low supply voltage force desingers to propose circuits working in the current mode to achieve sufficient signal to noise ratio. Furthermore, the frequency-limitation of the common operation amplifier leads to employing of other types of active elements. Active elements operating in the current mode can provide a high frequency bandwith and dynamic range [4]. Research in analog functional blocks is also focuded on the realization of the current-mode filters using different types of a current conveyor (CC) [9-11] and differential voltage current conveyor (DVCC) [12], [13]. We can mention filters with operational transconductance amplifiers (OTA) [14-15], current differencing transconductance amplifiers (CDTA) [16], [17]. Filters emploing fully differential current conveyors (FDCC) can be found in [18-20]. Papers [21], [22] describe various types of filters using current followers (CF). Furthermore, it is possible to come across filters operating with current differencing buffered amplifiers (CDBA) for instance in [23] and [24].

This article contains also fully-differential structures of proposed filters because of their advantages when compared to single-ended circuits such as lower harmonic distortion, greater dynamic range of the signal, greater attenuation of common-mode signal and better power supply rejection ratio. Fully-differential structures have also a few drawbacks namely the larger area taken on the chip which leads to higher power consumption and more complex design than single-ended structures [25], [26].

\section{ACTIVE ELEMENTS DEFINITION}

Description of two active elements used for proposal are presented in this section. Their schematic symbols and signal-flow graphs are included. Description also contains 2nd level macro-models of these elements used in simulations of behavior of proposed circuits.

To obtain low number of transfer function terms it is required employing multi-output active elements to create feedbacks, which allow us to cancel out unwanted terms of the transfer function [7]. Therefore, first used element is a multiple-output current follower (MO-CF) formerly presented in [27]. The MO-CF has on input and 4 output terminals. This component has been implemented using a universal current conveyor (UCC) [28], [29] as it is shown in Fig. 1. 
The relations between the input and outputs of the MO-CF are described by following equations:

$$
\begin{aligned}
& i_{\text {OUT } 1}=i_{\text {OUT } 3}=+i_{I N}, \\
& i_{\text {OUT } 2}=i_{\text {OUT } 4}=-i_{I N} .
\end{aligned}
$$

Its schematic symbol, simplified signal-flow graph and 2nd level model is shown in Fig. 1.

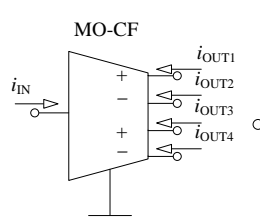

a)

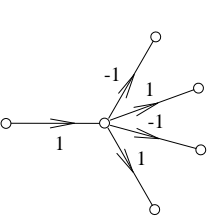

b)

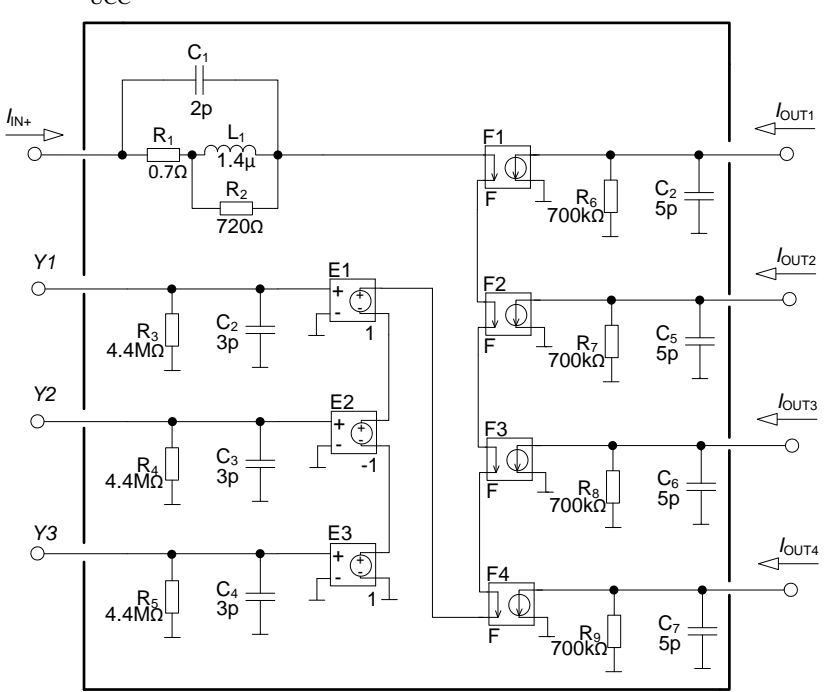

d)

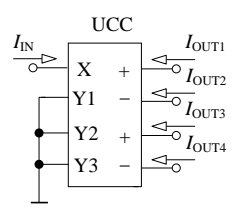

c)

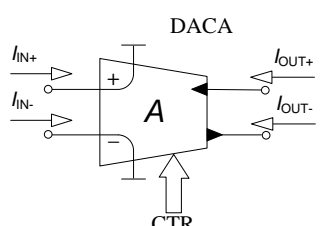

a)

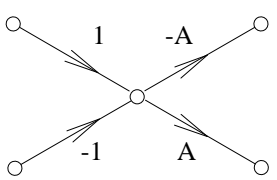

b)

\section{DACA}

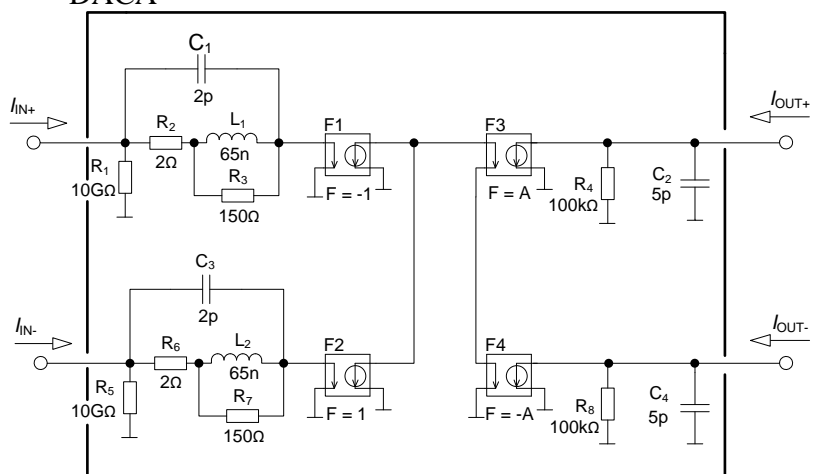

c)

Fig. 2. A digitally adjustable current amplifier a) schematic symbol, b) signal-flow graph, c) 2nd level macro-model

\section{III.PROPOSAL OF UNIVERSAL CURRENT-MODE FREQUENCY FILTERS}

\section{A. Description of the universal current-mode frequency filter}

Circuits of filters proposed in this paper are based on analysis of previously presented filter published in [32]. It is 2 nd order universal current-mode frequency filter. Scheme of this filter and its signal-flow graph can be seen in Fig. 3. It contains 3 multiple-output current followers and it is based on the fact that frequency filters of the second order can be made by appropriate setting of integrators [32].

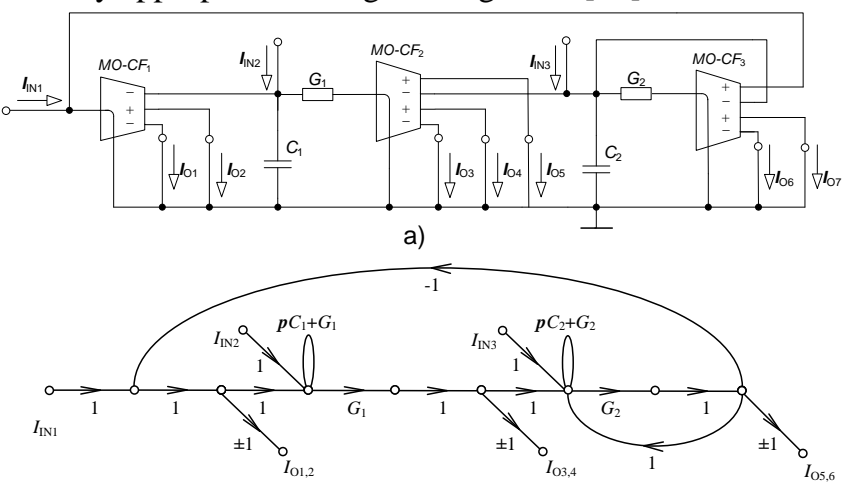

b)

Fig. 3. 2nd order universal current-mode frequency filter presented in [32]

The denominator of all transfer functions of this filter is equal to:

$D=s^{2} C_{1} C_{2}+s C_{2} G_{1}+G_{1} G_{2}$

Relation for the angular frequency and quality factor are:

$\omega_{0}=\sqrt{\frac{G_{1} G_{2}}{C_{1} C_{2}}}$,

$Q=\sqrt{\frac{G_{2} C_{1}}{G_{1} C_{2}}}$, 
where $\omega$ is angular frequency and $Q$ is the filter quality factor.

From Fig. 3 can be seen that all current responses are taken directly from high impedance outputs of the active elements. The original circuit was presented with only one input, but further analysis paid to this circuit showed that there can be 3 basic inputs. Specific transfer function can be obtained from the particular output, or summing of some outputs:

$$
\begin{aligned}
& I_{L P}=\frac{I_{O 7}}{I_{I N 1}}=\frac{I_{O 1}}{I_{I N 2}}=\frac{I_{O 7}}{I_{I N 2}}=\frac{I_{O 3}}{I_{I N 3}}=-\frac{I_{O 6}}{I_{I N 1}}= \\
& =-\frac{I_{O 2}}{I_{I N 2}}=-\frac{I_{O 6}}{I_{I N 2}}=-\frac{I_{O 4}}{I_{I N 3}}=\frac{G_{1} G_{2}}{D}, \\
& I_{B P}=\frac{I_{O 4}}{I_{I N 1}}=\frac{I_{O 4}}{I_{I N 2}}=\frac{I_{O 1}+I_{O 4}}{I_{I N 3}}=\frac{I_{O 7}+I_{O 4}}{I_{I N 3}}= \\
& =--\frac{I_{O 3}}{I_{I N 1}}=-\frac{I_{O 3}}{I_{I N 2}}=-\frac{I_{O 2}+I_{O 3}}{I_{I N 3}}=-\frac{I_{O 6}+I_{O 3}}{I_{I N 3}}= \\
& =\frac{s C_{2} G_{1}}{D}, \quad \\
& I_{H P}=\frac{I_{O 2}+I_{O 3}}{I_{I N 1}}=-\frac{I_{O 1}+I_{O 4}}{I_{I N 1}}=\frac{s^{2} C_{1} G_{2}}{D}, \\
& I_{B S}=\frac{I_{O 1}+I_{O 4}+I_{O 6}}{I_{I N 1}}=-\frac{I_{O 2}+I_{O 3}+I_{O 7}}{I_{I N 1}}= \\
& =-\frac{s^{2} C_{1} G_{2}+G_{1} G_{2}}{D}, \\
& I_{A P}=\frac{I_{O 1}+I_{O 4}+I_{O 5}+I_{O 6}}{I_{I N 1}}=-\frac{s^{2} C_{1} G_{2}-s C_{2} G_{1}+G_{1} G_{2}}{D} .
\end{aligned}
$$

The aim of designers of integrated circuits is that proposed filters should be universal. In other words, a filter should be able of realizing all types of filtering functions (low pass, band pass, high pass, band stop and all pass filter). From equations (9-13) is evident that this filter provides all types of the transfer functions, moreover, all types of these functions except an all pass filter are presented even in inverted form.

B. Proposal of new 2nd order universal current-mode frequency filters

Based on the rules of M-C graphs, new filters have been proposed using the filter presented in [32] as a pattern. First of them can been seen in Fig. 4. In this case, 2 digitally adjustable current amplifiers have been added. By changing the current gain of these amplifiers, the pole frequency of the filter can be adjusted independently of the quality factor. Fig. 5. shows the fully-differential version of the first proposed filter. Both F-D versions of proposed filters are designed with non-differential current followers instead of fully differential current followers (FDCFs) in order of easier implementation in form of PCB.

The denominator for the transfer functions of this filter is given by:

$D=s^{2} C_{1} C_{2}+s C_{2} G_{1} A_{1}+G_{1} G_{2} A_{1} A_{2}$.
In order to obtain particular transfer functions for the F-D filters factor $A$ has to be replaced by $2 A$ because of the differential gain of the DACA, which is twice higher than in case of $\mathrm{S}-\mathrm{E}$ structures as is demonstrated by equation (5). The same applies for $G_{1}, G_{2}$ when their values must be twice higher than in case of S-E conductances. From equation (14) is obvious that in case $A_{1}=A_{2}=A$ it is possible to control the pole frequency of the filter independently of the quality factor of the filter by adjusting this parameter. That is proven by following relations expressing the relationship between the pole frequency and quality factor.

$f_{0}=\frac{A}{2 \pi} \sqrt{\frac{G_{1} G_{2}}{C_{1} C_{2}}}$

$Q=\sqrt{\frac{G_{2} C_{1}}{G_{1} C_{2}}}$.

We can see that, $Q$ is not depended on $A$ parameter and that is why this parameter will not change when $A$ is changing. Following equations represent the transfer functions of this filter:

$$
\begin{aligned}
& I_{L P 1}=-\frac{I_{O 6}}{I_{I N 1}}=-\frac{I_{O 6}}{I_{I N 2}}=\frac{I_{O 5}}{I_{I N 1}}=\frac{I_{O 5}}{I_{I N 2}}=\frac{G_{1} G_{2} A_{1}}{D}, \\
& I_{L P 2}=-\frac{I_{O 3}}{I_{I N 4}}=\frac{I_{O 4}}{I_{I N 4}}=\frac{G_{1} G_{2} A_{2}}{D}, \\
& I_{L P 3}=-\frac{I_{O 6}}{I_{I N 5}}=\frac{I_{O 5}}{I_{I N 5}}=\frac{G_{1} G_{2} A_{1} A_{2}}{D}, \\
& I_{B P 1}=-\frac{I_{O 4}}{I_{I N 1}}=-\frac{I_{O 4}}{I_{I N 2}}=\frac{I_{O 3}}{I_{I N 1}}=\frac{I_{O 3}}{I_{I N 2}}=\frac{s C_{2} G_{1}}{D}, \\
& I_{B P 2}=\frac{I_{O 6}}{I_{I N 3}}=-\frac{I_{O 5}}{I_{I N 3}}=\frac{s C_{1} G_{2} A_{1}}{D}, \\
& I_{B P 3}=-\frac{I_{O 2}}{I_{I N 4}}=\frac{I_{O 1}}{I_{I N 4}}=\frac{s C_{1} G_{2} A_{2}}{D}, \\
& I_{B P 4}=-\frac{I_{O 4}}{I_{I N 5}}=\frac{I_{O 3}}{I_{I N 5}}=\frac{s C_{2} G_{1} A_{1} A_{2}}{D}, \\
& I_{H P 1}=-\frac{I_{O 2}}{I_{I N 1}}=\frac{I_{O 1}}{I_{I N 1}}=\frac{s^{2} C_{1} C_{2}}{D}, \\
& I_{H P 2}=-\frac{I_{O 2}}{I_{I N 5}}=\frac{I_{O 1}}{I_{I N 5}}=\frac{s^{2} C_{1} C_{2} A_{2}}{D}, \\
& I_{B S 1}=-\frac{I_{O 2}+I_{O 6}}{I_{I N 1}}=\frac{I_{O 1}+I_{O 5}}{I_{I N 1}}=\frac{s^{2} C_{1} C_{2}+G_{1} G_{2} A_{1}}{D}, \\
& I_{B S 2}=-\frac{I_{O 2}+I_{O 6}}{I_{I N 5}}=\frac{I_{O 1}+I_{O 5}}{I_{I N 5}}= \\
& =\frac{s^{2} C_{1} C_{2} A_{2}+G_{1} G_{2} A_{1} A_{2}}{D},
\end{aligned}
$$




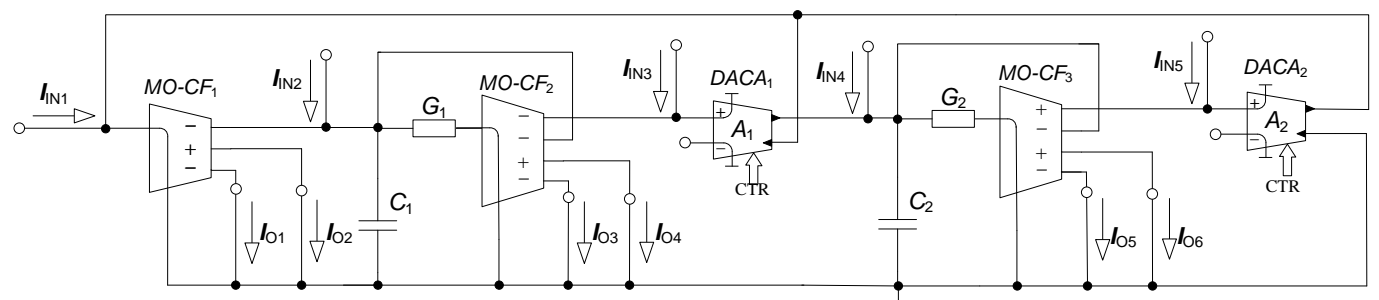

a)

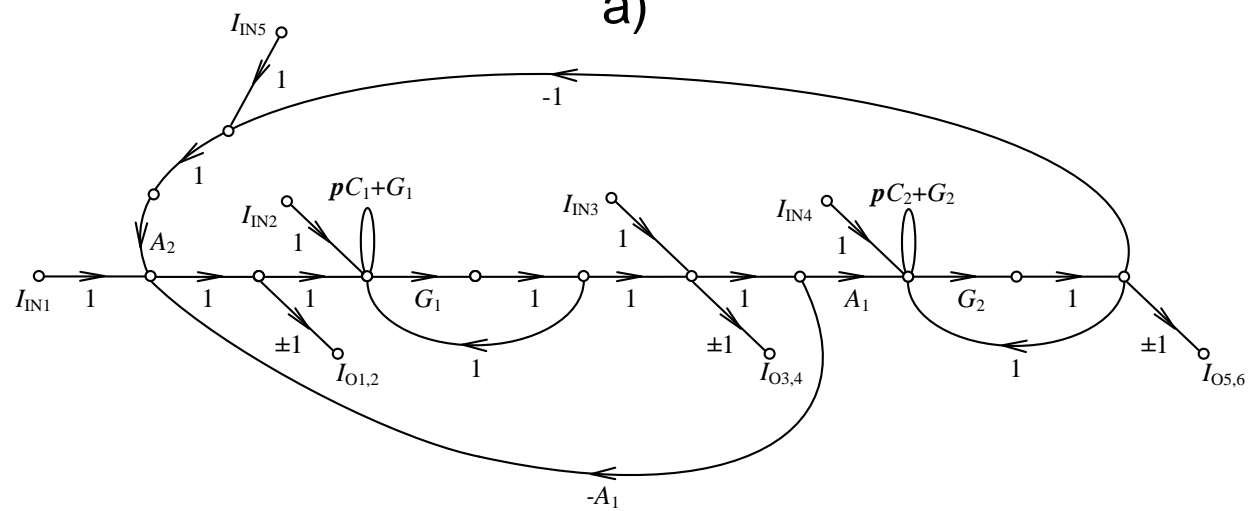

b)

Fig. 4. First proposed 2nd order universal current-mode frequency using 2 DACAs S-E version a) scheme, b) signal-flow graph

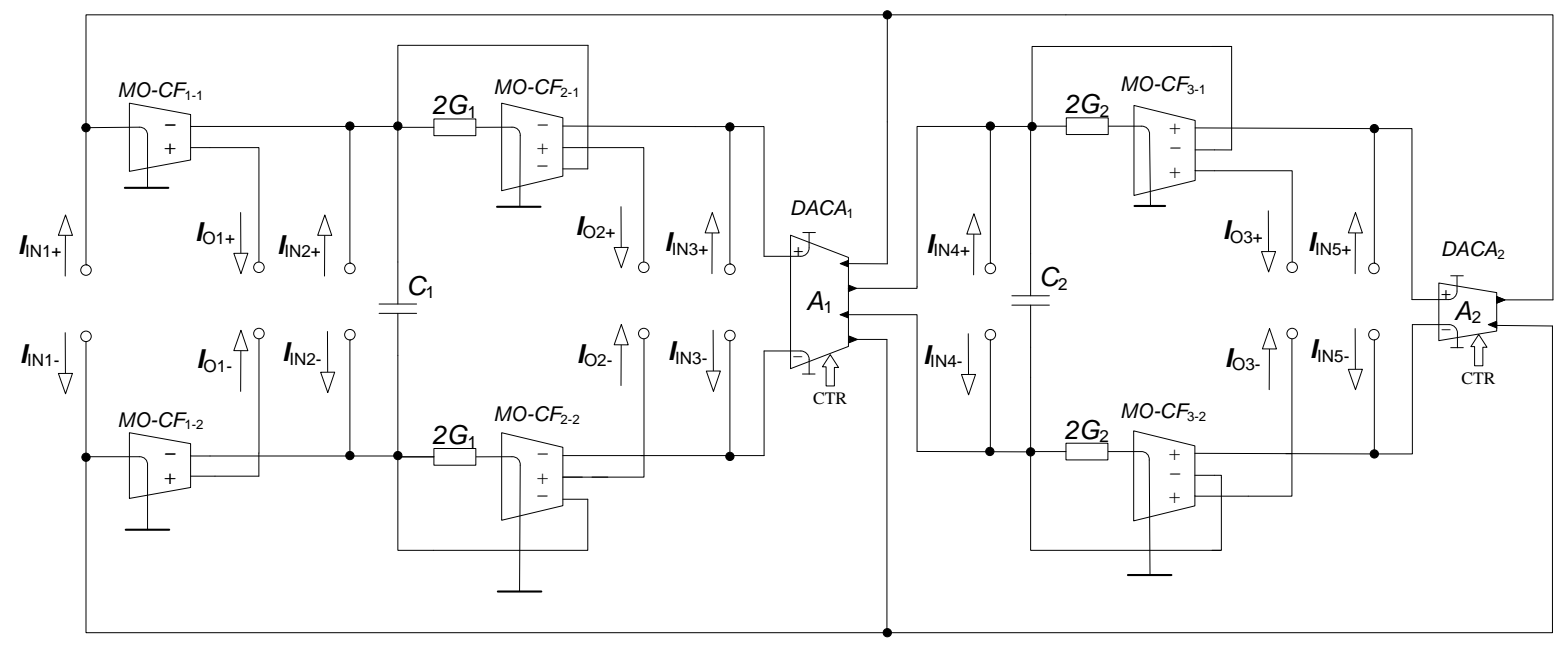

a)

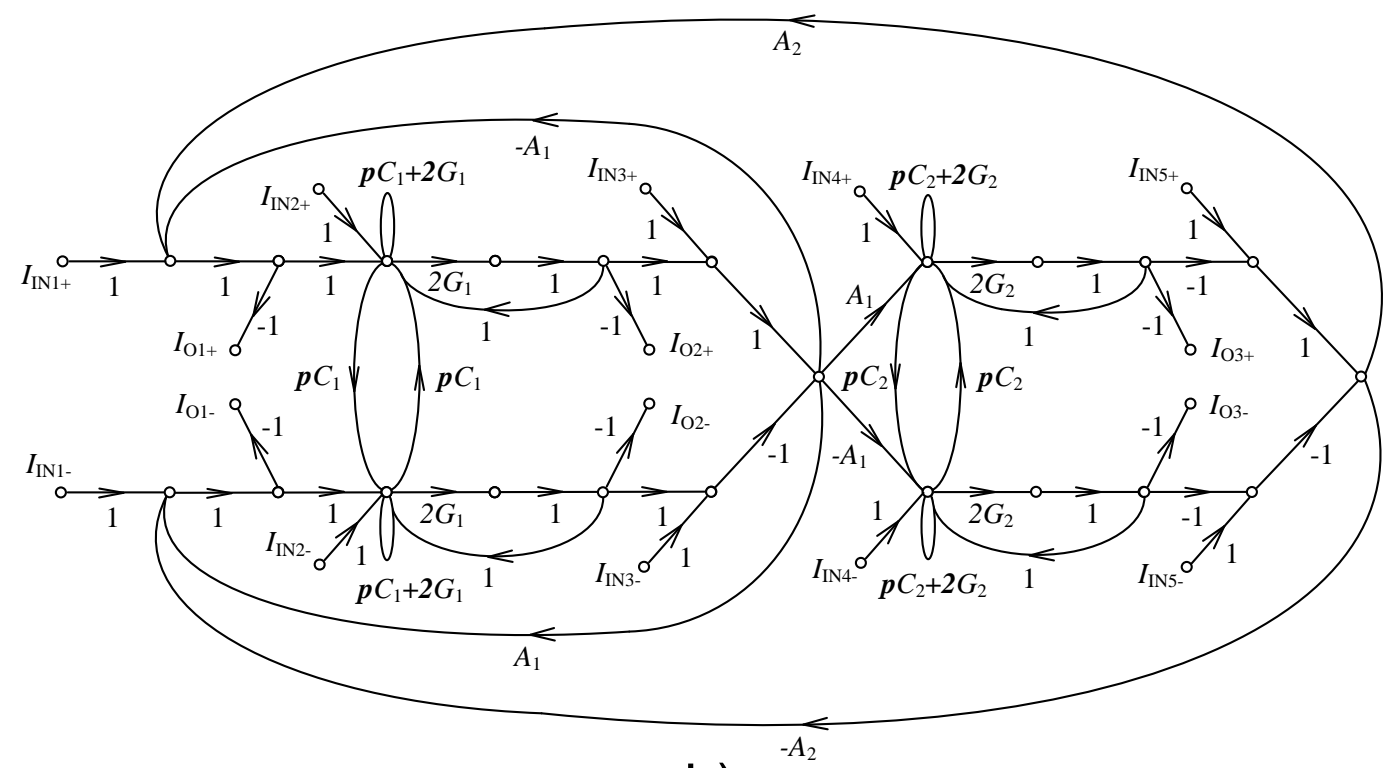

b)

Fig. 5. First proposed 2nd order universal current-mode frequency using 2 DACAs F-D version a) scheme, b) signal-flow graph 

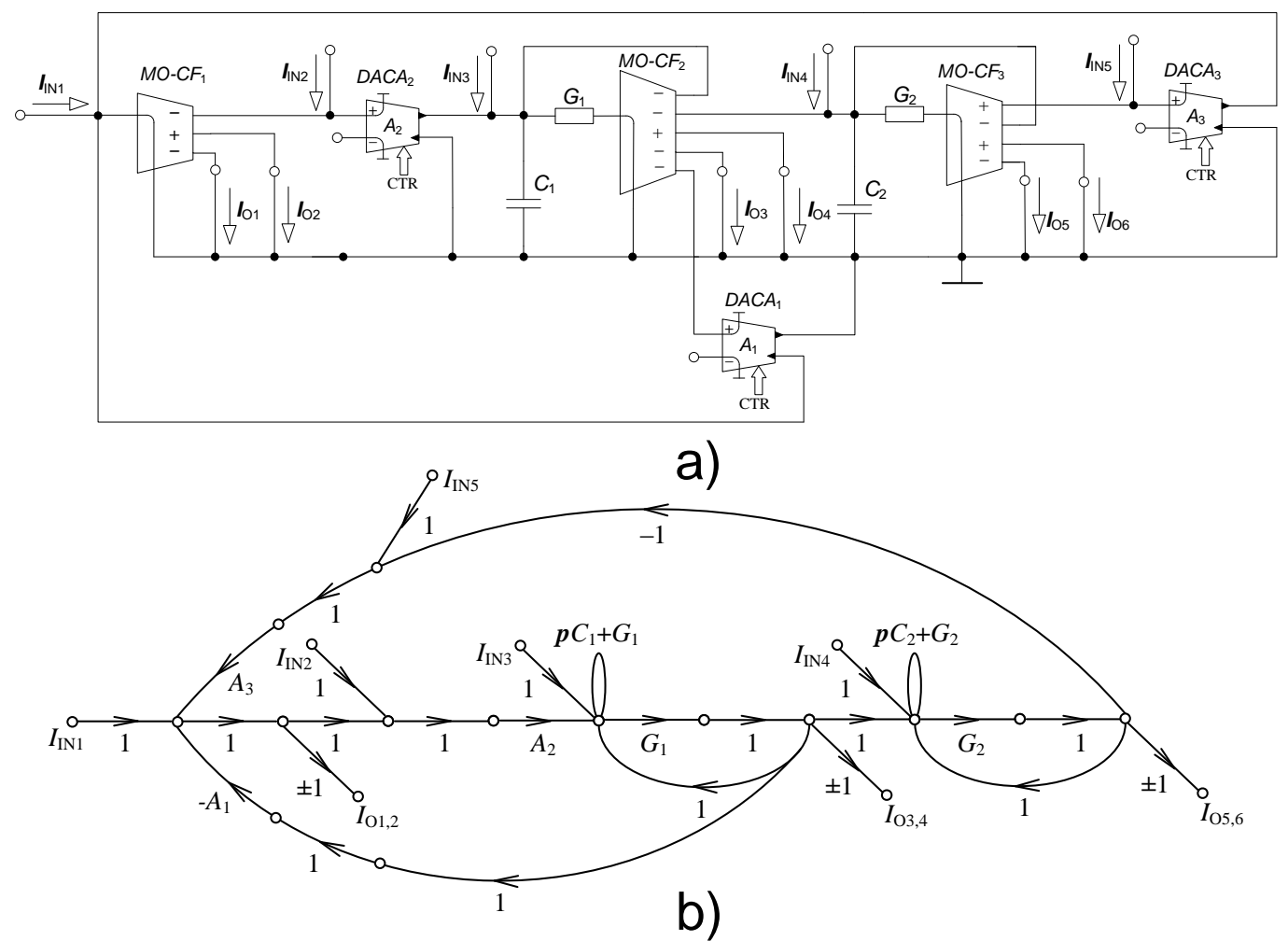

Fig. 6. Second proposed 2nd order universal current-mode frequency using 3 DACAs S-E version a) scheme, b) signal-flow graph
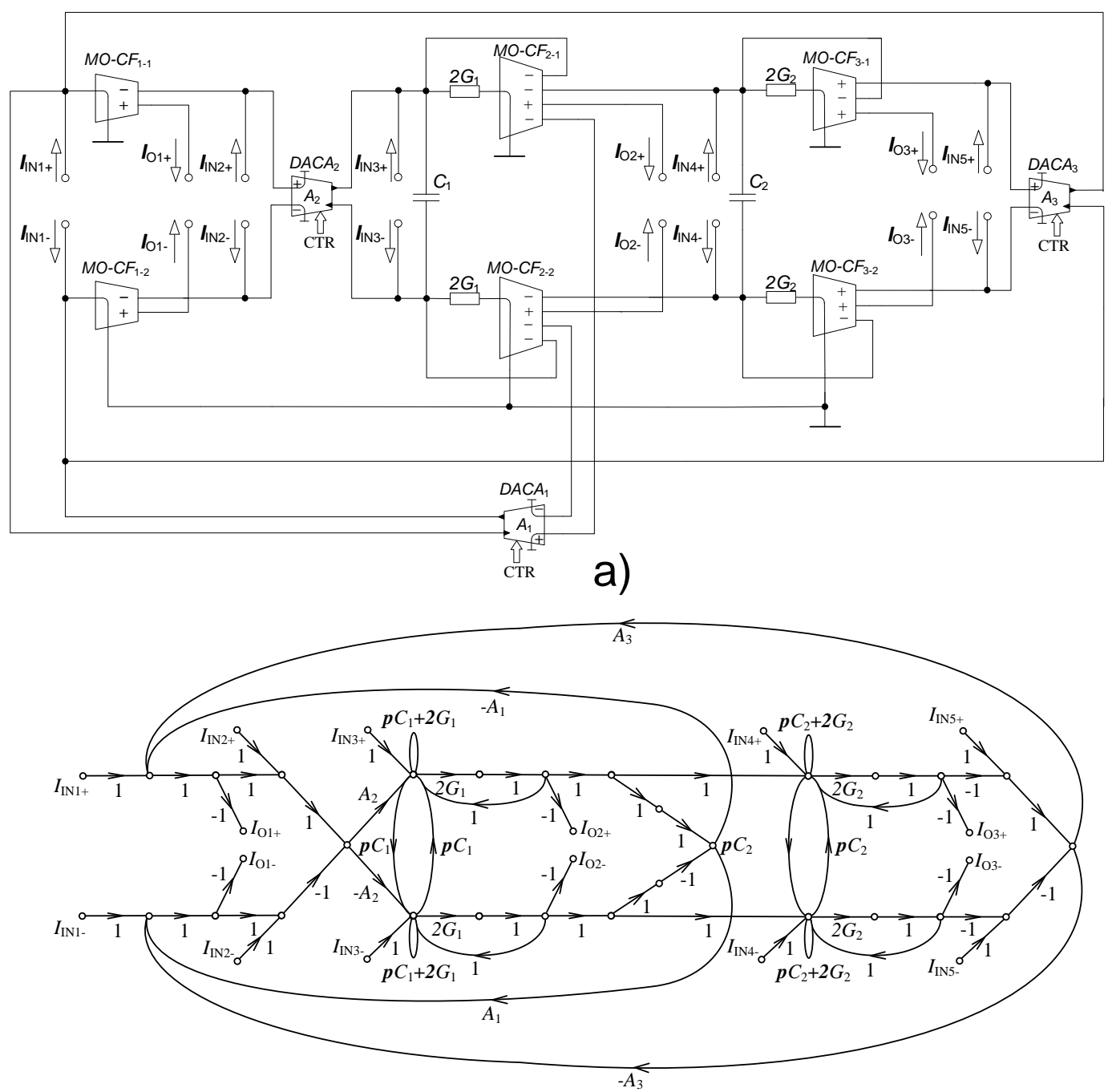

b)

Fig. 7. Second proposed 2nd order universal current-mode frequency using 3 DACAs F-D version a) scheme, b) signal-flow graph 


$$
\begin{aligned}
& I_{A P 1}=-\frac{I_{O 2}+I_{O 3}+I_{O 6}}{I_{I N 1}}=\frac{I_{O 1}+I_{O 4}+I_{O 5}}{I_{I N 1}}= \\
& =\frac{s^{2} C_{1} C_{2}-s C_{2} G_{1}+G_{1} G_{2} A_{1}}{D}, \\
& I_{A P 2}=-\frac{I_{O 2}+I_{O 3}+I_{O 6}}{I_{I N 5}}=\frac{I_{O 1}+I_{O 4}+I_{O 5}}{I_{I N 5}}= \\
& =\frac{s^{2} C_{1} C_{2} A_{2}-s C_{2} G_{1} A_{2}+G_{1} G_{2} A_{1} A_{2}}{D},
\end{aligned}
$$

where $A_{1}, A_{2}$ is a current gain of $\mathrm{DACA}_{1}, \mathrm{DACA}_{2}$ respectively.

These equations show the fact that we can obtain high pass transfer function directly from the outputs of MO-CF1 to compare to previous circuit when it was necessary to sum two appropriate outputs in order to get high pass transfer function. This applies for the filter with 3 DACAs, too, that will be presented later.

Figure 6 and Fig. 7 respectively show a single-ended and fully-differential version of the filter using 3 digitally adjustable current amplifiers. That allows us to control both the pole frequency and quality filter independently of each other.

Parameter $A_{1}$ is used to adjust the quality factor. By common change of parameters $A_{2}$ and $A_{3}$ we can set the pole frequency of the filter.

The denominator of this filter is:

$$
D=s^{2} C_{1} C_{2}+s C_{2} G_{1} A_{1} A_{2}+G_{1} G_{2} A_{2} A_{3} .
$$

This equation gives the possibility of controlling of the pole frequency and quality factor independently of each other by adjusting $A_{1}$ in order to change the quality factor and simultaneous change of $A_{2}$ and $A_{3}$ when $A_{2}=A_{3}=A$ to control the pole frequency as is proven by:

$f_{0}=\frac{A}{2 \pi} \sqrt{\frac{G_{1} G_{2}}{C_{1} C_{2}}}$,

$Q=\frac{1}{A_{1}} \sqrt{\frac{G_{2} C_{1}}{G_{1} C_{2}}}$.

The transfer functions are described by:

$$
\begin{aligned}
& I_{L P 1}=-\frac{I_{O 6}}{I_{I N 1}}=\frac{I_{O 5}}{I_{I N 1}}=-\frac{I_{O 6}}{I_{I N 2}}=\frac{I_{O 5}}{I_{I N 2}}=\frac{G_{1} G_{2} A_{2}}{D}, \\
& I_{L P 2}=-\frac{I_{O 6}}{I_{I N 3}}=\frac{I_{O 5}}{I_{I N 3}}=\frac{G_{1} G_{2}}{D}, \\
& I_{L P 3}=-\frac{I_{O 3}}{I_{I N 4}}=\frac{I_{O 4}}{I_{I N 4}}=-\frac{I_{O 6}}{I_{I N 5}}=\frac{I_{O 5}}{I_{I N 5}}=\frac{G_{1} G_{2} A_{2} A_{3}}{D}, \\
& I_{B P 1}=-\frac{I_{O 4}}{I_{I N 1}}=\frac{I_{O 3}}{I_{I N 1}}=-\frac{I_{O 4}}{I_{I N 2}}=\frac{I_{O 3}}{I_{I N 2}}=\frac{s C_{2} G_{1} A_{2}}{D},
\end{aligned}
$$

$$
\begin{aligned}
& I_{B P 2}=-\frac{I_{O 4}}{I_{I N 3}}=\frac{I_{O 3}}{I_{I N 3}}=\frac{s C_{2} G_{1}}{D}, \\
& I_{B P 3}=-\frac{I_{O 2}}{I_{I N 4}}=\frac{I_{O 1}}{I_{I N 4}}=\frac{s C_{1} G_{2} A_{3}}{D}, \\
& I_{B P 4}=-\frac{I_{O 4}}{I_{I N 5}}=\frac{I_{O 3}}{I_{I N 5}}=\frac{s C_{2} G_{1} A_{2} A_{3}}{D}, \\
& I_{H P 1}=-\frac{I_{O 2}}{I_{I N 1}}=\frac{I_{O 1}}{I_{I N 1}}=\frac{s^{2} C_{1} C_{2}}{D}, \\
& I_{H P 2}=-\frac{I_{O 2}}{I_{I N 5}}=\frac{I_{O 1}}{I_{I N 5}}=\frac{s^{2} C_{1} C_{2} A_{3}}{D}, \\
& I_{B S 1}=-\frac{I_{O 2}+I_{O 6}}{I_{I N 1}}=\frac{I_{O 1}+I_{O 5}}{I_{I N 1}}=\frac{s^{2} C_{1} C_{2}+G_{1} G_{2} A_{2}}{D}, \\
& I_{B S 2}=-\frac{I_{O 2}+I_{O 6}}{I_{I N 5}}=\frac{I_{O 1}+I_{O 5}}{I_{I N 5}}= \\
& =\frac{s^{2} C_{1} C_{2} A_{3}+G_{1} G_{2} A_{2} A_{3}}{D}, \\
& I_{A P}=-\frac{I_{O 2}+I_{O 3}+I_{O 6}}{I_{I N 1}}=\frac{I_{O 1}+I_{O 4}+I_{O 5}}{I_{I N 1}}= \\
& =\frac{s^{2} C_{1} C_{2}-s C_{2} G_{1} A_{2}+G_{1} G_{2} A_{2}}{D}, \\
& I_{A P}=-\frac{I_{O 2}+I_{O 3}+I_{O 6}}{I_{I N 5}}=\frac{I_{O 1}+I_{O 4}+I_{O 5}}{I_{I N 5}}= \\
& =\frac{s^{2} C_{1} C_{2} A_{3}-s C_{2} G_{1} A_{2} A_{3}+G_{1} G_{2} A_{2} A_{3}}{D},
\end{aligned}
$$

where $A_{1}, A_{2}$ and $A_{3}$ are current gains of $\mathrm{DACA}_{1}, \mathrm{DACA}_{2}$ and $\mathrm{DACA}_{3}$.

Transfer functions which correspond with a specific term of the denominator of the filter have unity gain in pass-band area regardless values of A parameters, therefore, these transfer functions are most advantageous. That applies for transfer functions from equations (19), (24), (35) and (40). Band pass transfer functions containing $C_{1}$ capacitor instead of $C_{2}$ which is involved in both denominates of proposed filters have not unity gain and the smallest attenuation starts at $-5 \mathrm{~dB}$. That applies for equations (21), (22) and (38). Other transfer functions change their gain according values of parameter $A$. In case of proposed filters from Figs. 4 and 5 when comparing low pass transfer functions namely equations (17), (18) and (19), low pass transfer function from equation (17) using $I_{\mathrm{IN} 2}$ has greater attenuation at higher frequencies.

The same applies for band pass transfer functions from equation (20) when using $I_{\mathrm{IN} 2}$ and equation (21). Comparing high pass and band stop functions, transfer function from equations (24) and (26) have slightly greater attenuation at higher frequencies. Transfer functions of proposed filters from Figs. 6 and 7 provide greater attenuation at higher frequencies in case of low pass and band pass functions from equations (34), (37) and then (33) and (36) when $I_{\mathrm{IN} 2}$ input is 
used. High pass and band stop functions from equations (40) and (42) provide slightly greater attenuation at higher frequencies. Comparison has been carried out using starting values of specific filter parameters specified in chapter 4 .

\section{Simulations}

To verify appropriate functions of proposed filters, simulations of these circuits were carried out using simulating program OrCAD and Snap. Some simulation results are included in this paper for illustration. All output responses illustrated in Figs. 8, 9, 12, 13, 14, 17 and 18 are inverting filtering functions. Output responses illustrated in Figs. 10, 11, 15 and 16 are non-inverting. Models of active elements used in simulations are shown in Fig. 1 and 2 in chapter 1. Following values of specific filter parameters have been chosen for PSpice simulations the starting pole frequency $f_{0}=1 \mathrm{MHz}$, Butterworth approximation $Q=0.707$ (starting value), $C_{1}=C_{2}=100 \mathrm{pF}$ and starting values of parameters $A_{1}=A_{2}=A_{3}=1$ (half values in case of F-D filters). Because a real part of DACA is still in the testing phase we are using alternative element which allows us to set any value of its gain in range of 0-5 continuously, therefore, values chosen to verify ability to change the pole frequency or quality factor of proposed filters are solely demonstrational and do not necessary correspond with values which can be obtained using a real element of DACA amplifier. Remaining values of passive elements were calculated according equation (46), (47) respectively.

$$
\begin{aligned}
& R_{1}=\frac{Q}{2 \pi f_{0} C_{1}}=1125 \Omega \\
& R_{2}=\frac{1}{4 \pi^{2} f_{0}^{2} C_{1} C_{2} R_{1}}=2252 \Omega
\end{aligned}
$$

Proposed fully-differential filters are designed that way they have almost the same transfer functions as proposed single-ended filters due to modified values of passive elements:

$$
\begin{aligned}
& R_{1}=\frac{1125}{2}=563 \Omega \\
& R_{2}=\frac{2252}{2}=1126 \Omega
\end{aligned}
$$

In order to obtain particular transfer functions for the F-D filters factor $A$ has to be replaced by $2 A$ because of the differential gain of DACA, which is twice higher than in case of S-E structures as is demonstrated by equation (5).

Outputs of both S-E and F-D filter structures with 2 DACAs from Fig. 4 and Fig. 5 can be seen in Fig 8 when $I_{\mathrm{IN} 1}$ input has been used and output responses are taken from outputs $I_{\mathrm{O} 2}$ (blue line), $I_{\mathrm{O} 4}$ (red line), $I_{\mathrm{O} 6}$ (green line) and $I_{\mathrm{O} 2}+$ $I_{\mathrm{O} 6}$ (turquoise line) in case of S-E form of the filter and $I_{\mathrm{O} 1}$ (blue line), $I_{\mathrm{O} 2}$ (red line), $I_{\mathrm{O} 3}$ (green line) and $I_{\mathrm{O} 1}+I_{\mathrm{O} 3}$ (turquoise line) for F-D form.

Gain, delay and phase characteristics of all pass filter can be seen in Fig. 9 when outputs $I_{\mathrm{O} 2}+I_{\mathrm{O} 3}+I_{\mathrm{O} 6}$ for S-E form and $I_{\mathrm{O} 1}+I_{\mathrm{O} 2}+I_{\mathrm{O} 3}$ in case of F-D form were used. From the graph can be see that the filter is suitable only approximately up to frequency of $10 \mathrm{MHz}$ because of bandwidth limitations of used active elements. The same applies for the second proposed filter.

Figure 10 shows the transient analysis of this all pass filter where blue line represents the input signal, red and green lines are the output responses of S-E form, F-D form respectively. Amplitude of the input signal has been set to $1 \mathrm{~mA}$ and frequency $1 \mathrm{MHz}$ when the signal of non-inverting output should have its phase shifted of $180^{\circ}$ opposed to the input signal. From the picture can be seen that the F-D filter is closer to the expected value.

Transient analysis of band-pass transfer functions of filters from Figs. 4 and 5 can be seen in Fig. 11. Graph shows the input signal and output responses of band-pass transfer functions of filters from Figs. 4 and 5 to a unit step of value of $1 \mathrm{~mA}$ when $I_{\mathrm{IN} 1}$ input and $I_{\mathrm{O} 3}$ output in case of S-E filter and $I_{\mathrm{O} 2}$ output in case of F-D filter have been used. It's important to note that used simulation models of active elements are designed mainly for AC analysis. That also applies for transient analysis of filters from Figs. 6 and 7.

Figure 12 demonstrates possibility of adjusting the pole frequency of proposed S-E filter by changing the current gain of DACAs when $I_{\mathrm{IN} 1}$ input has been used and output responses are taken from output $I_{\mathrm{O} 2}$ in case of $\mathrm{S}-\mathrm{E}$ form and $I_{\mathrm{O} 1}$ in case of F-D form. Values of parameter $A$ have been set $A_{1}=A_{2}=\{0.5,1,2\}$. Calculated values of the pole frequency for both S-E and F-D solutions and for chosen values of parameter $A$ were $\{499.95 \mathrm{kHz}, 999.91 \mathrm{kHz}, 1999.81 \mathrm{kHz}$. Measured values obtained from simulation were $\{466.48$ $\mathrm{kHz}, 921.54 \mathrm{kHz}, 1816.23 \mathrm{kHz}\}$ for S-E form of proposed filter using 2 DACAs and $\{479.34 \mathrm{kHz}, 942.31 \mathrm{kHz}, 1846.38$ $\mathrm{kHz}\}$ in case of F-D form.

Figure 13 shows the transfer functions of S-E and F-D filters with 3 DACAs from Fig. 6 and Fig. 7. The input used in this case is $I_{\mathrm{IN} 1}$ and output responses are taken from outputs $I_{\mathrm{O} 2}$ (blue line), $I_{\mathrm{O} 4}$ (red line), $I_{\mathrm{O} 6}$ (green line) and $I_{\mathrm{O} 2}+I_{\mathrm{O} 6}$ (turquoise line) in case of S-E form and $I_{\mathrm{O} 1}$ (blue line), $I_{\mathrm{O} 2}$ (red line), $I_{\mathrm{O} 3}$ (green line) and $I_{\mathrm{O} 1}+I_{\mathrm{O} 3}$ (turquoise line) for F-D form.

Figure 14 shows delay and phase characteristics of all pass filter when outputs $I_{\mathrm{O} 2}+I_{\mathrm{O} 3}+I_{\mathrm{O} 6}$ for S-E form and $I_{\mathrm{O} 1}+$ $I_{\mathrm{O} 2}+I_{\mathrm{O} 3}$ in case of F-D form were used.

The transient analysis of this all pass filter can be seen in Fig. 15 where blue line represents the input signal, red and green lines are the output responses of S-E form, F-D form respectively. Parameters of the input signal have been chosen evenly like for the previous all pass filter, consequently, amplitude of the input was $1 \mathrm{~mA}$ and frequency $1 \mathrm{MHz}$ From the picture can be again seen that the output response of the F-D filter is closer to the expected value.

Figure 16 shows the input signal and output responses of band-pass transfer functions of filters from Figs. 6 and 7 to a unit step of value of $1 \mathrm{~mA}$ when $I_{\mathrm{IN} 1}$ input and $I_{\mathrm{O} 3}$ output in case of S-E filter and $I_{\mathrm{IN} 1}$ output in case of F-D filter have been used.

The ability of tuning parameters quality factor $Q$ and pole frequency $f_{0}$ independently of each other can be seen in Fig. 17, 18 respectively. The input was $I_{\mathrm{IN} 1}$ and the output responses were $I_{\mathrm{O} 2}\left(\mathrm{~S}-\mathrm{E}\right.$ form), $I_{\mathrm{O} 1}$ (F-D form) when the possibility of controlling $f_{0}$ has been analyzed and $I_{\mathrm{O} 4}(\mathrm{~S}-\mathrm{E}$ form) and $I_{\mathrm{O} 2}$ (F-D form) in case of quality factor adjusting. Gains of DACAs were set as follow $A_{1}=\{0.1,0.5,1\}$ and $A_{2}, A_{3}=\{0.5,1,2\}$. Calculated values of the pole frequency were the same as for previously described filter. Measured values obtained from simulation for the $\mathrm{S}-\mathrm{E}$ form were 


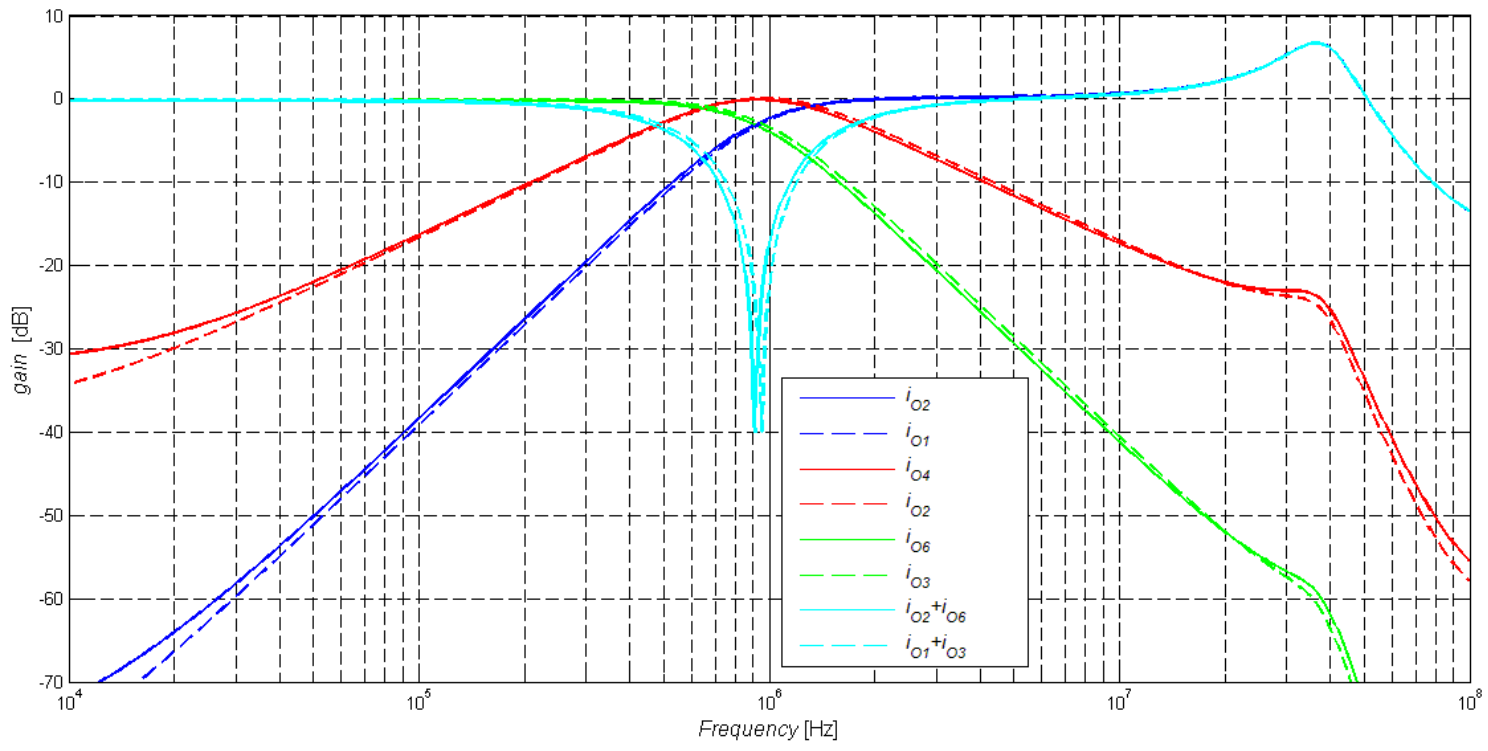

Fig. 8. Output responses of the S-E filter from Fig. 4 (solid lines) and of the F-D filter from Fig. 5 (dashed lines): high pass, band pass, low pass, band stop when $I_{\mathrm{IN} 1}$ has been used

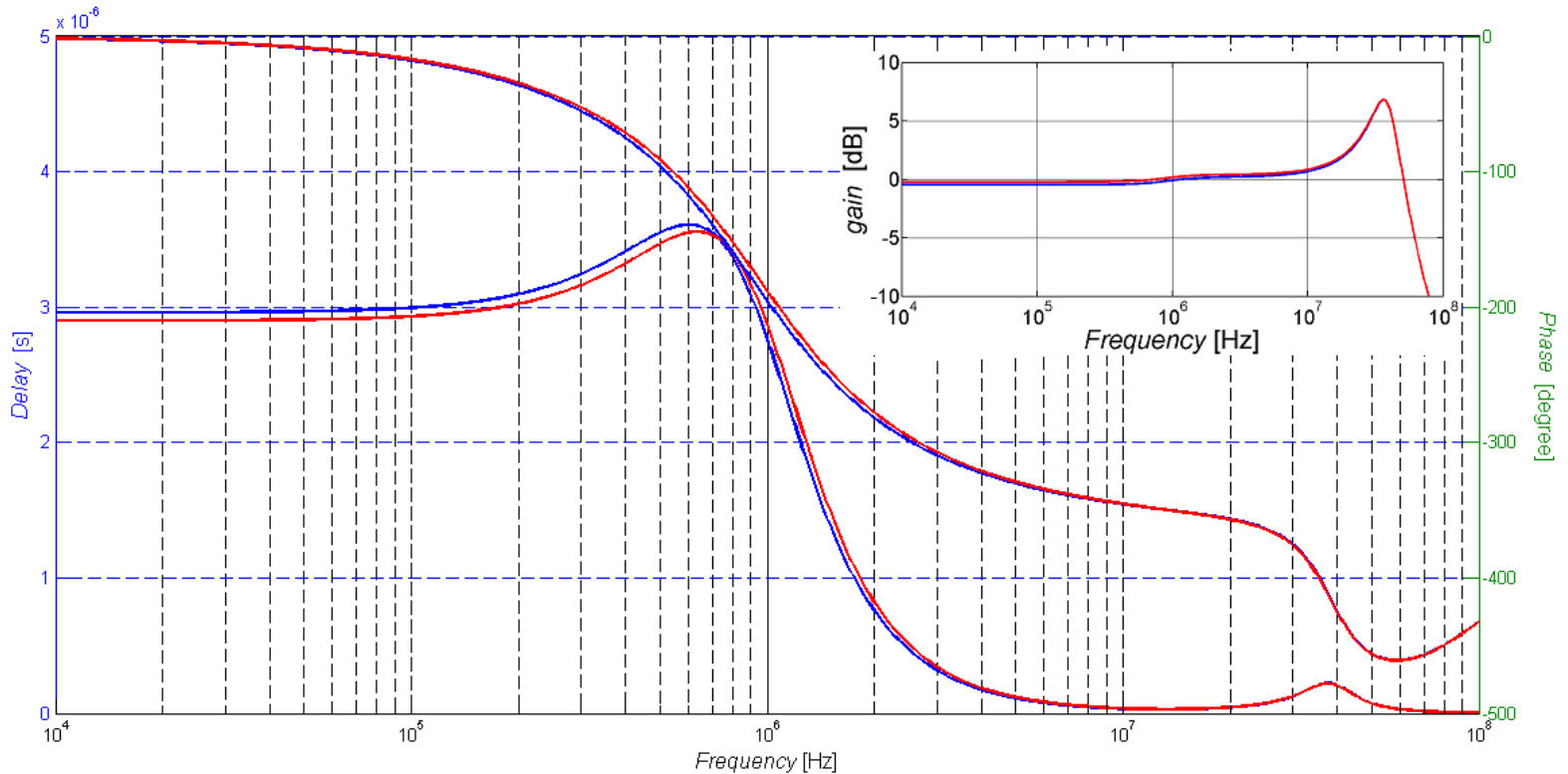

Fig. 9. Output responses of all pass filter characteristics (gain, delay and phase) of the S-E filter from Fig. 4 (blue lines) and of the F-D filter from Fig. 5 (red lines)

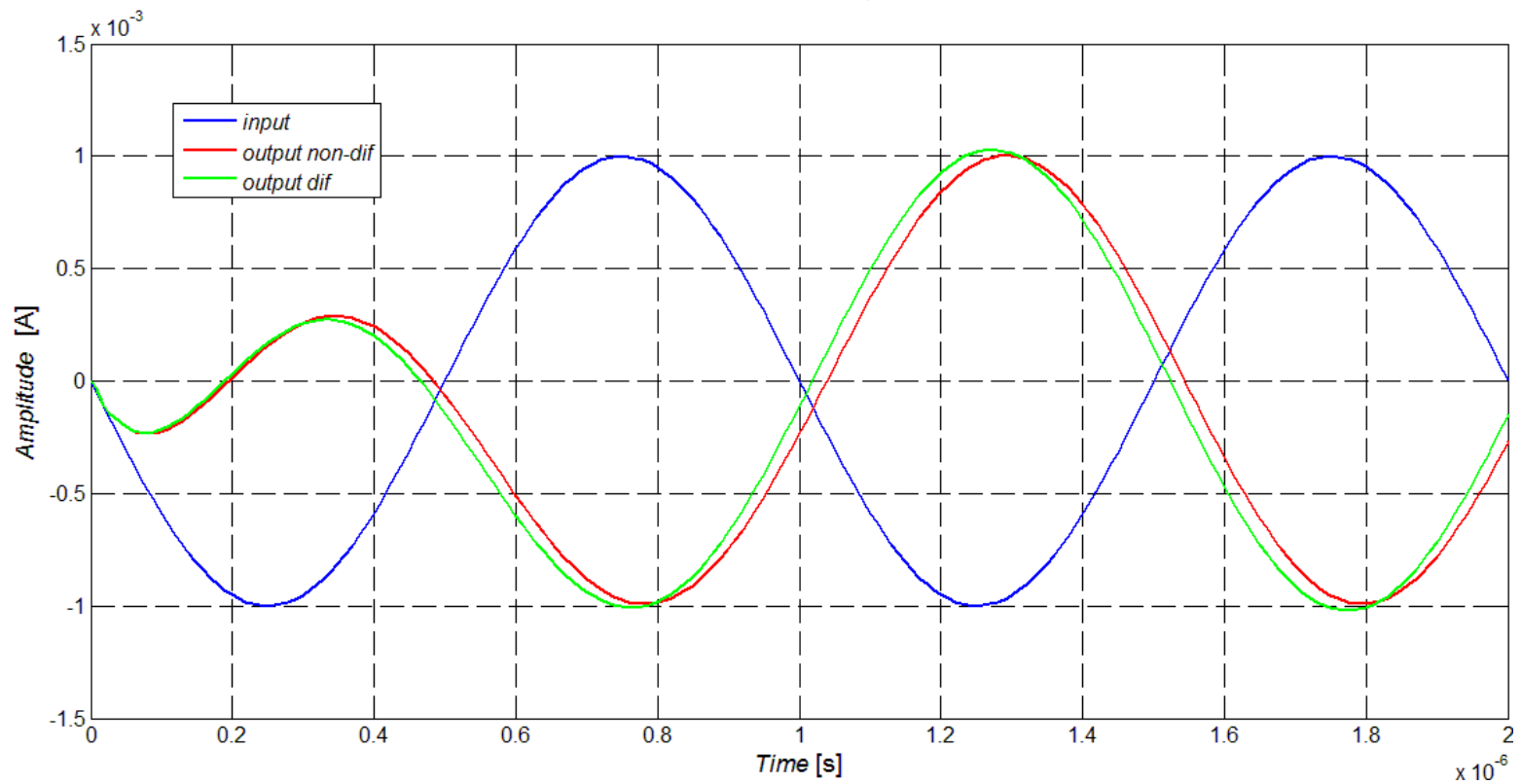

Fig. 10. Input signal and output responses of all pass filter (transient analysis) of filters from Figs. 4 and 5 when the input frequency was $1 \mathrm{MHz}$ and amplitude $1 \mathrm{~mA}$ 


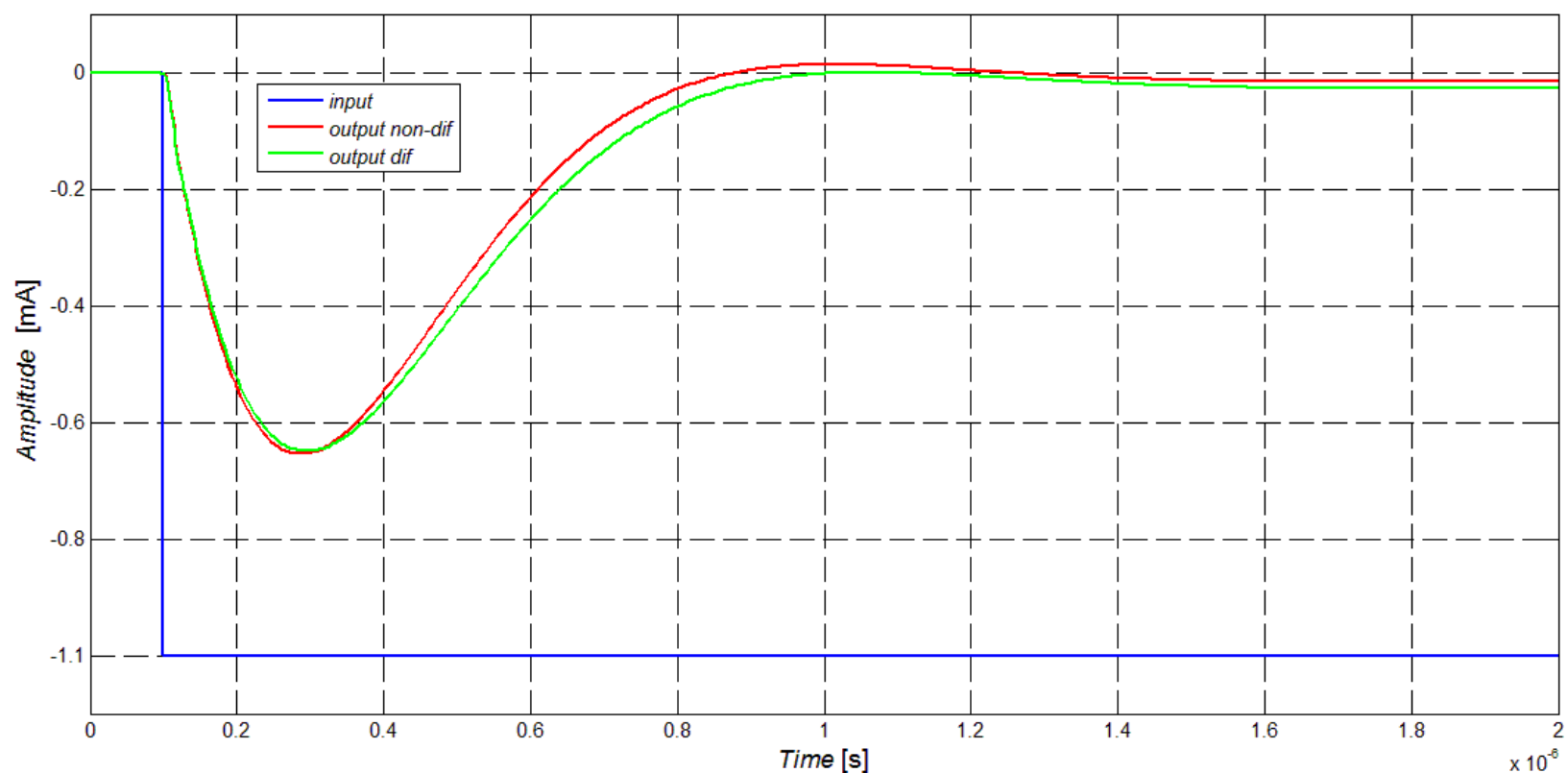

Fig. 11. Input signal and output responses of band-pass filtering functions of proposed filters from Figs. 4 and 5 to a unit step signal of value of $1 \mathrm{~mA}$

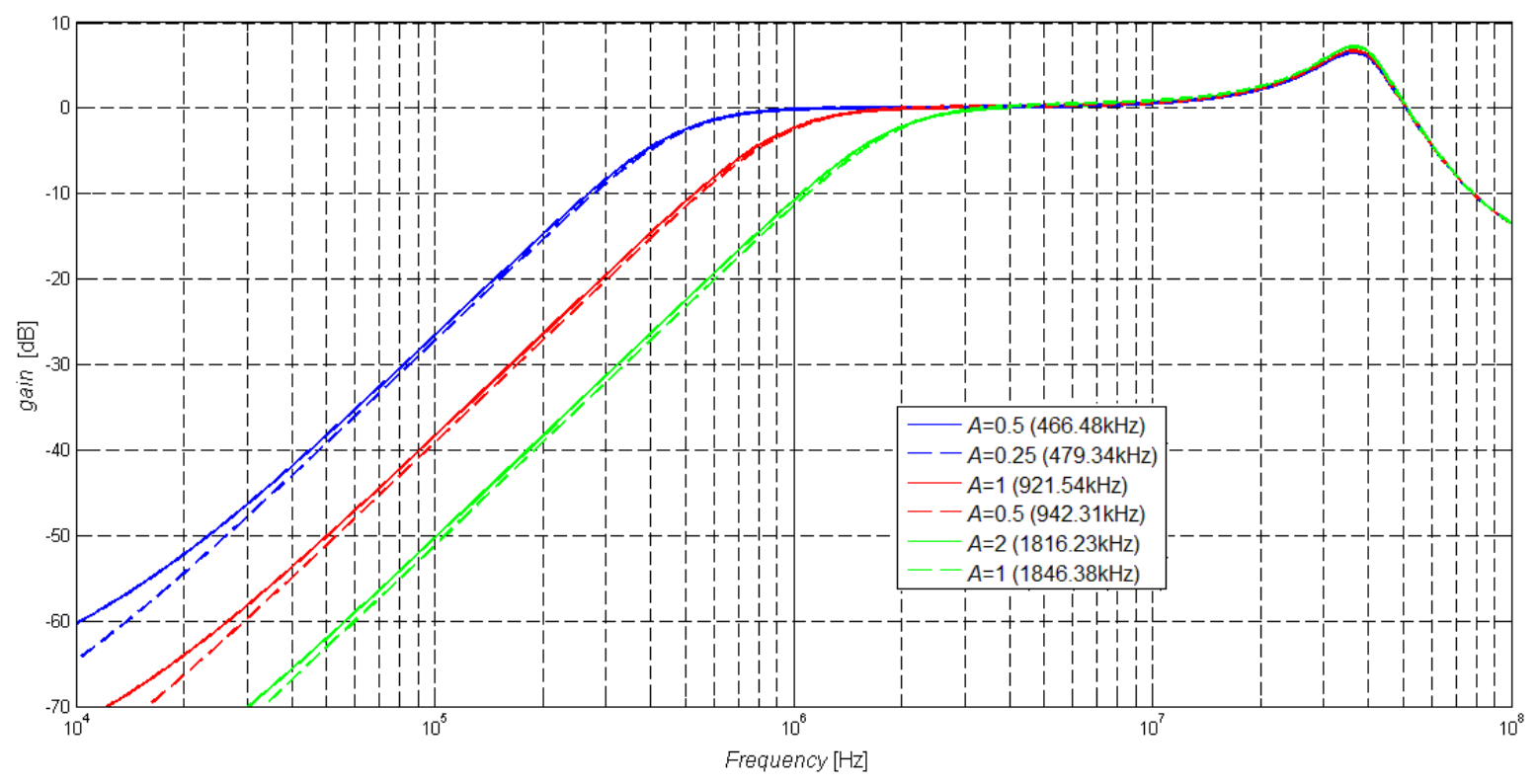

Fig. 12. Demonstration of controlling $f_{0}$ in case of the S-E filter from Fig. 4 (solid lines) and of the F-D filter from Fig. 5 (dashed lines) when $\mathrm{A}_{1}=\mathrm{A}_{2}$ were set $0.5,1$, and 2

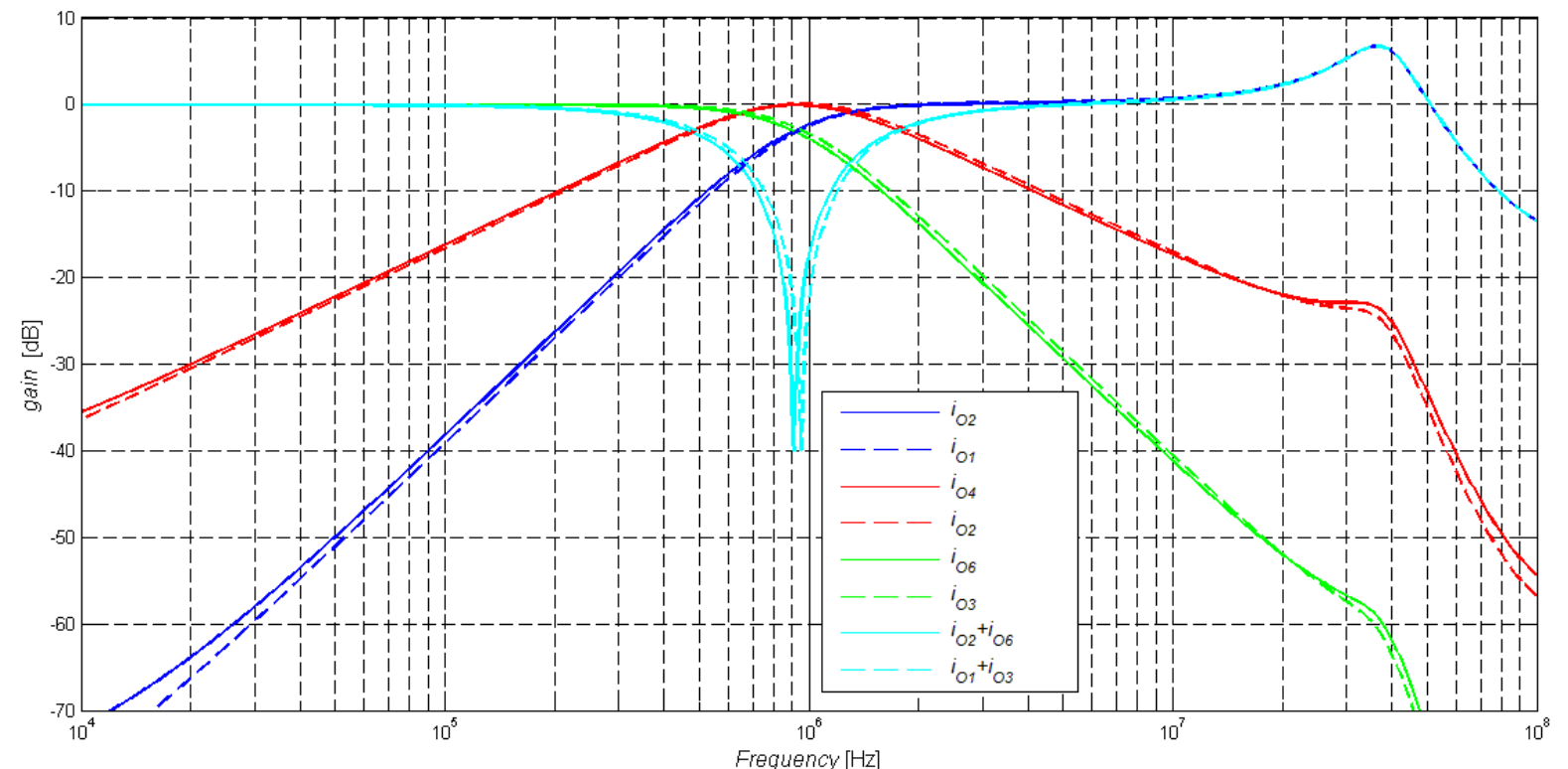

Fig. 13. Output responses of the S-E filter from Fig. 6 (solid lines) and pf the F-D filter from Fig. 7 (dashed lines): high pass, band pass, low pass, band stop when $I_{\mathrm{IN} 1}$ has been used 


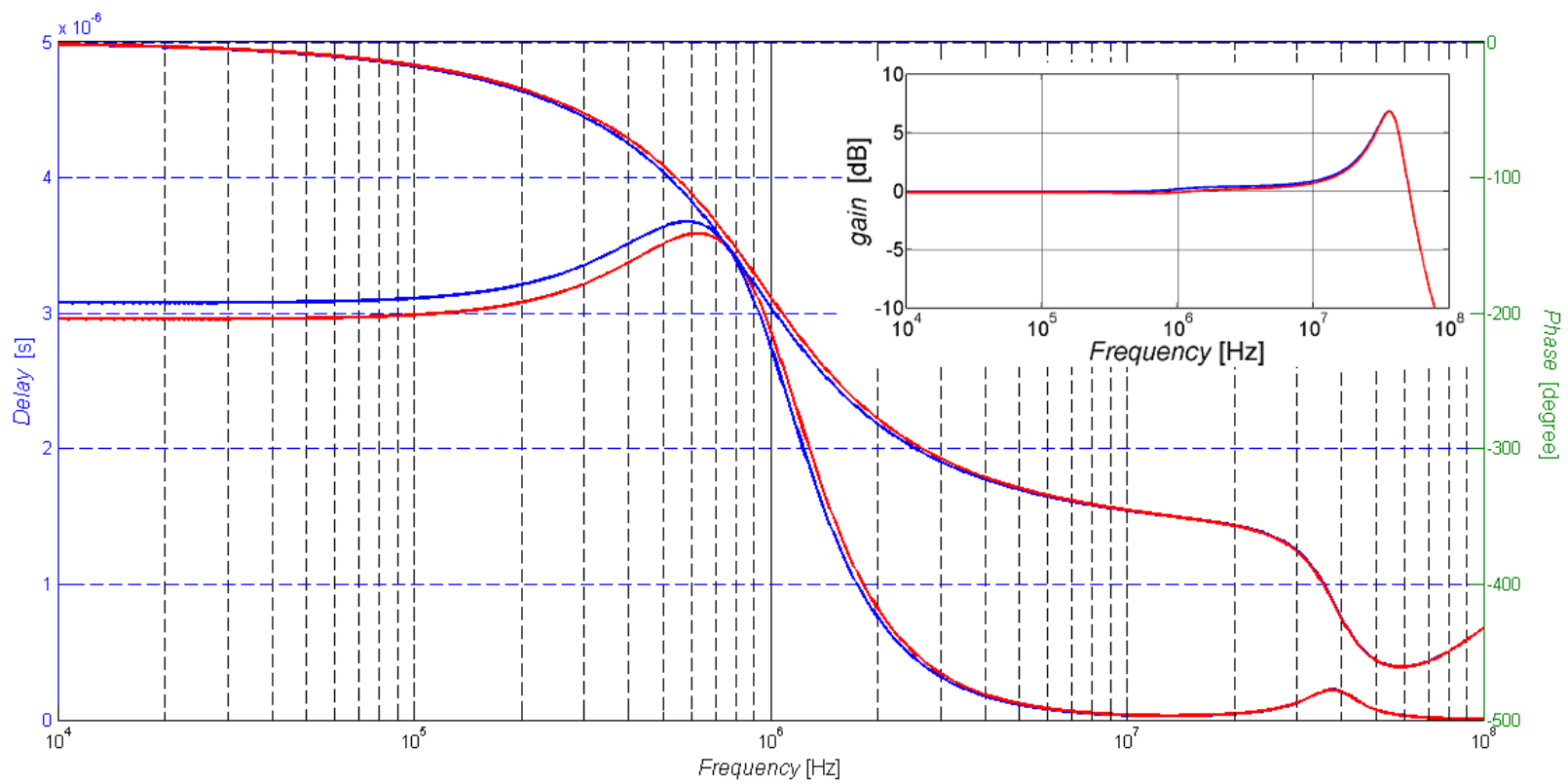

Fig. 14. Output responses of All pass filter characteristics (gain, delay and phase) of the S-E filter from Fig. 4 (blue lines) and of the F-D filter from Fig. 5 (red lines)

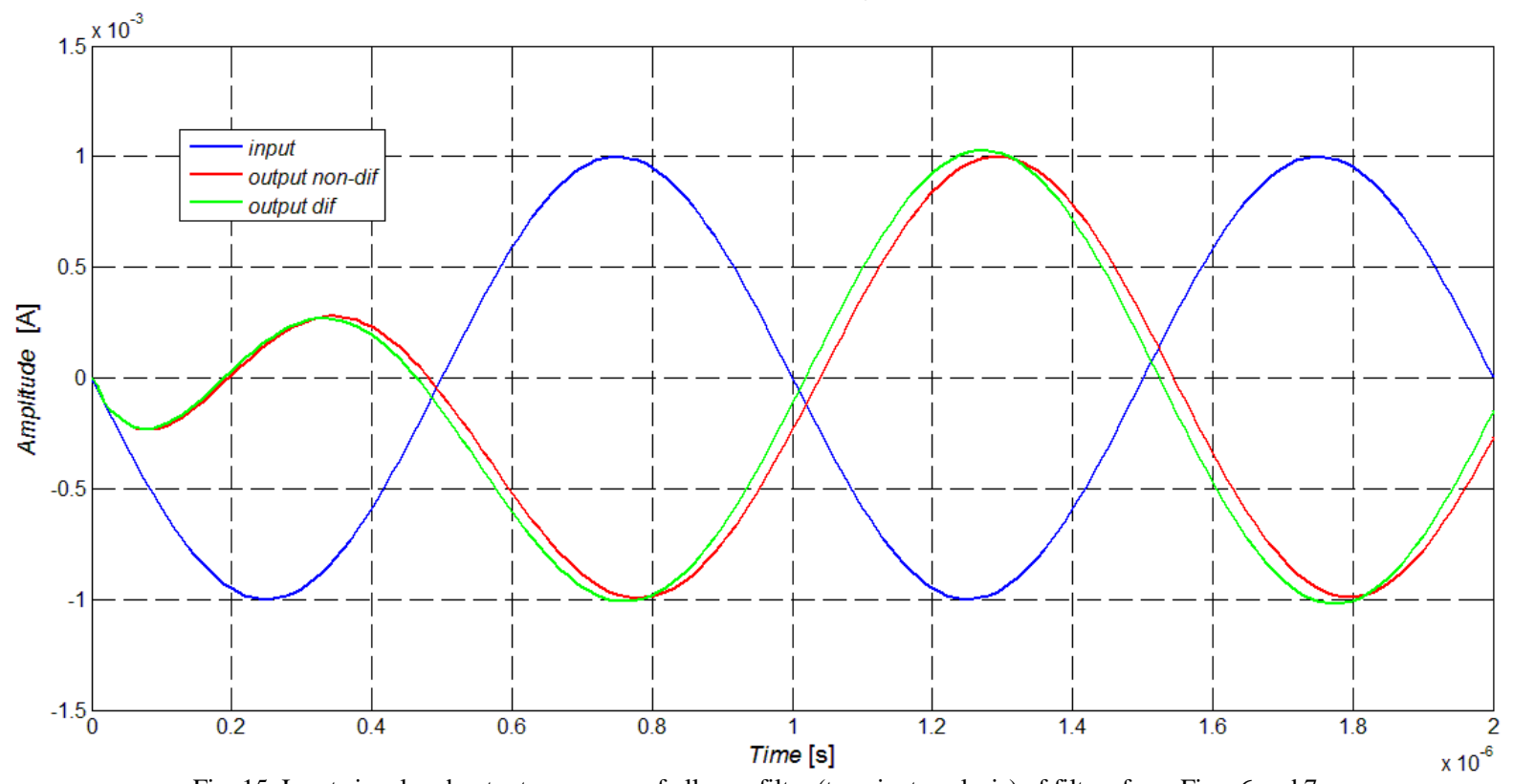

Fig. 15. Input signal and output responses of all pass filter (transient analysis) of filters from Figs. 6 and 7 when the input frequency was $1 \mathrm{MHz}$ and amplitude $1 \mathrm{~mA}$

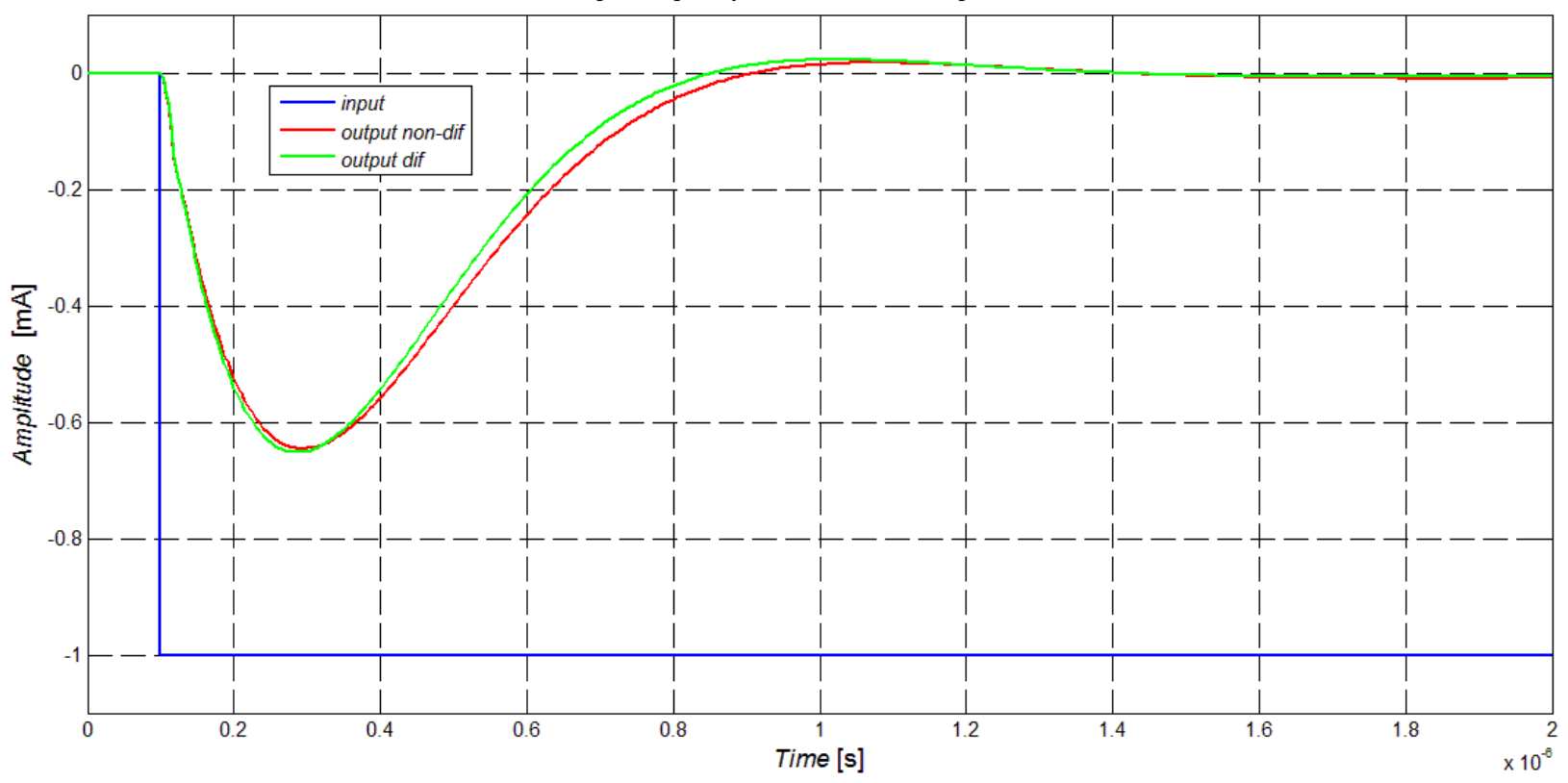

Fig. 16. Input signal and output responses of band-pass filtering functions of proposed filters from Figs. 6 and 7 to a unit step signal of value of $1 \mathrm{~mA}$ 


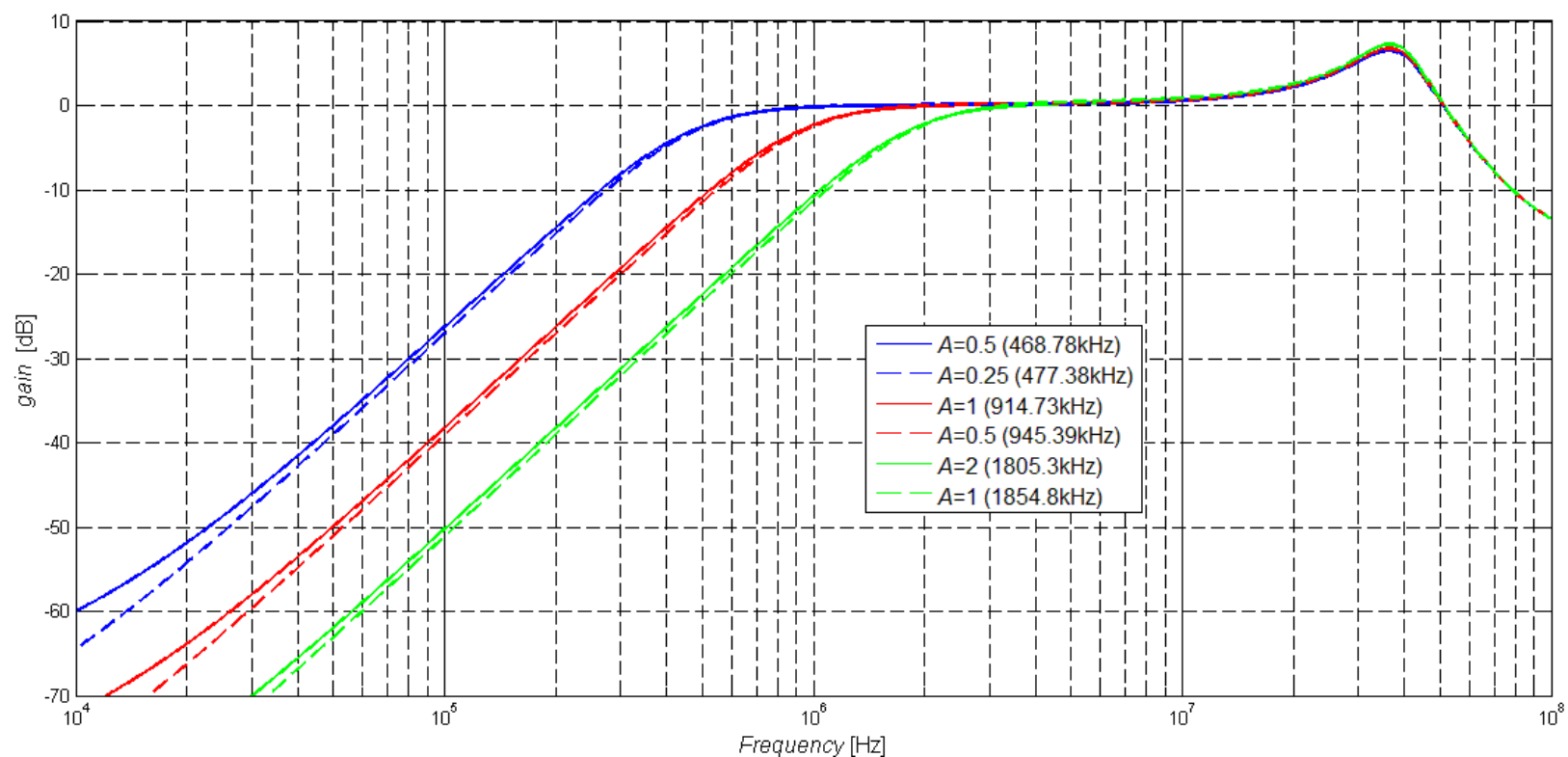

Fig. 17. Demonstration of controlling $f_{0}$ in case of the S-E filter from Fig. 6 (solid lines) and of the F-D filter from Fig. 7 (dashed lines) when $\mathrm{A}_{2}=\mathrm{A}_{3}$ were set $0.5,1$, and 2

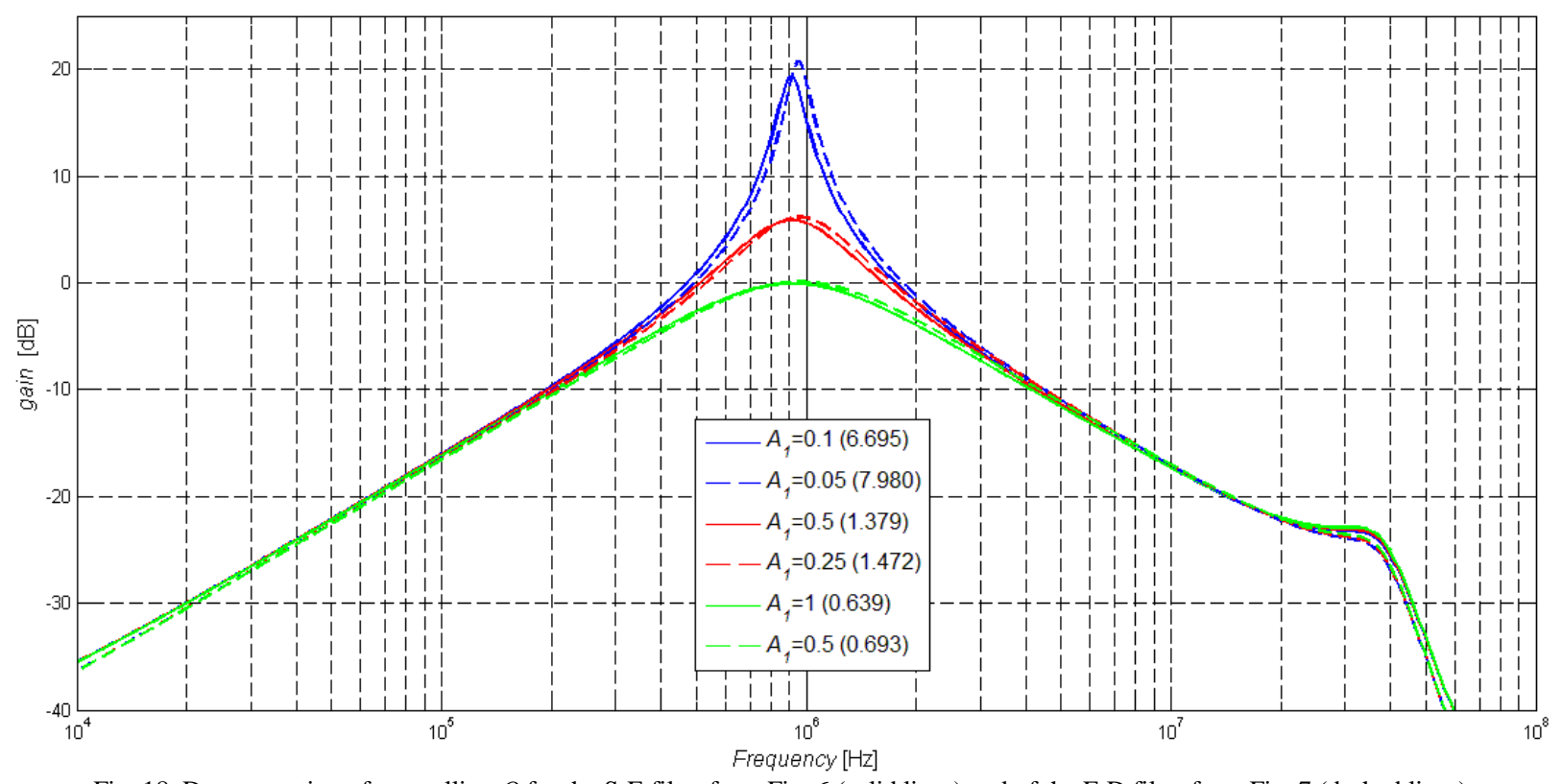

Fig. 18. Demonstration of controlling $Q$ for the S-E filter from Fig. 6 (solid lines) and of the F-D filter from Fig. 7 (dashed lines) when $\mathrm{A}_{1}$ was set $0.1,0.5$, and 1

$\{468.78 \mathrm{kHz}, 914.73 \mathrm{kHz}, 1805.3 \mathrm{kHz}\}$ and $\{477.38 \mathrm{kHz}$, $945.39 \mathrm{kHz}, 1854.8 \mathrm{kHz}\}$ in case of the F-D form. Calculated values of the quality factor were $\{7.068,1.414,0.707\}$ and simulated for the S-E form $\{6.695,1.379,0.639\}$ and $\{7.980$, $1.472,0.693\}$.

From Figs. 8-18 we can compare S-E and F-D output responses of proposed filters. The graphs show magnitude responses of non-inverting low pass, band pass and high-pass transfer functions. The F-D filters provide a slightly higher attenuation than the S-E structures. In this case the difference is most probably caused by unequal values of resistors since the values of resistors used in F-D structures must be a half of resistance used for $\mathrm{S}-\mathrm{E}$ structures to obtain the same transfer functions. The pole frequencies of F-D filters are also closer to calculated values. Simulation results shown in Fig. 12, Fig. 17 and Fig. 18 confirm the ability of controlling the pole frequency and quality factor of proposed filters.

\section{V.CONCLUSION}

Two new 2nd order universal filters proposed using signal-flow graphs method were presented in this paper. Both filters operate in the current-mode and both filters were proposed in single-ended and fully-differential form. In both proposals were placed digitally adjustable current amplifiers (DACAs) to control the pole frequency and quality factor of the filters. First designed filter uses 2 DACAs to adjust the pole frequency independently of the quality factor. In case of the second proposed filter there are used 3 DACAs to control both the pole frequency and quality factor independently of each other. From transfer functions of proposed circuits it is obvious that the filters are universal. Simulations verified functions of proposed circuits and some of them are included for illustration to compare S-E and F-D structures and illustrating possibility of controlling the pole frequency and quality factor. 


\section{ACKNOWLEDGEMENT}

Research described in this letter is supported by Czech Science Foundation project 102/09/1681. The described research was performed in laboratories supported by the SIX project; the registration number CZ.1.05/2.1.00/03.0072, the operational program Research and Development for Innovation.

\section{REFERENCES}

[1] J. JERABEK, J. KOTON, K. VRBA, "A Generalized Method of Multifunctional Frequency Filter Design" (Zobecněná metoda návrhu multifunkčních kmitočtových filtrů), Elektrorevue - Internet Journal (http://www.elektrorevue.cz), No. 41, 2007, pp. 41-1 - 41-10.

[2] N. HERENCSAR, K. VRBA, " The Common Approach to Designing of Frequency Filters Based on Autonomous Circuits" (Obecný prístup $\mathrm{k}$ návrhu kmitočtových filtrů pomocí autonomních obvodů), Elektrorevue - Internet Journal (http://www.elektrorevue.cz), No. 40, 2006, pp. 40-1 - 40-17.

[3] J. KOTON, K. VRBA, "Designing of Frequency Filters Using Autonomous Circuit With a Full Admittance Network" (Návrh kmitočtových filtrů pomocí autonomního obvodu s úplnou sítí admitancí), Elektrorevue - Internet Journal (http://www.elektrorevue.cz), No. 33, 2005.

[4] J. KOTON, K. VRBA, "Zobecněné metody návrhu kmitočtových filtrů" (Generalized Methods of Frequency Filter Design), Elektrorevue - Internet Journal (http://www.elektrorevue.cz), No. 26 , 2008, pp. 26-1 - 26-17.

[5] J. KOTON, K. VRBA, "Electronically Tunable Frequency Filters Based on Transformation Cells", In The Third International Conference Systems, Cancun, 2008, pp. 260-264.

[6] P. BRANDSTETTER, L. KLEIN, "Design of Frequency Filters by Method of Synthetic Immittance Elements with Current Conveyors", In Proc. International Conference Applied Electronics $(A E)$, Pilsen, Czech Republic, Sep. 2012, pp. 37 - 40

[7] J. JERABEK, K. VRBA, " The Proposal of Tunable Frequency Filter With Current Active Elements Using Signal-Flow Graphs Method" (Návrh přeladitelného kmitočtového filtru s proudovými aktivními prvky za pomoci metody grafu signálových toků), Elektrorevue Internet Journal (http://www.elektrorevue.cz), No. 42, 2009, pp. 42-1 42-7.

[8] K. INTAWICHAI, W. TANGSRIRAT, "Signal-Flow Graph Realization of nth-Order Current-Mode Allpass Filters Using CFTAs", In Proc. The 10th International Conference Electrical Engineering/Electronics, Computer, Telecommunications and Information Technology (ECTI-CON), Krabi, Thailand, May 2013, pp. $1-6$

[9] E. YUCE, "Current-mode electronically tunable biquadratic filters consisting of only CCCIIs and grounded capacitors", Microelectronics Journal, Vol. 40, No. 12, Dec. 2009, pp. 1719-1725.

[10] M. KUMNGERN, "Multiple-input single-output current-mode universal filter using translinear current conveyors", Journal of Electrical and Electronics Engineering Research, Vol. 3(9), Nov. 2011, pp. 162-170.

[11] H. CHEN, "Current-mode dual-output ICCII-based tunable universal biquadratic filter with low-input and high-output impedances", Int. J. Circuit Theory and Applications, 2012, DOI: 10.1002/cta.1858.

[12] S. MINAEI', M. A. IBRAHIP, H. KUNTUAN, "A New Current-Mode KHN-Biquad Using Differential Voltage Current Conveyor Suitable for IF Stages", In Proc. The Seventh International Symposium Signal Processing and Its Applications, Paris, France, 2003, Vol. 1, Jul. 2003, pp. $249-252$.

[13] H. CHEN, "Tunable versatile current-mode universal filter based on plus-type DVCCs", AEU - International Journal of Electronics and Communications, Vol. 66, No. 4, Apr. 2012, pp. 332-339.

[14] M. T. ABUELMA'ATTI, A. BENTRCIA, "A novel mixed-mode OTA-C universal filter", International Journal of Electronics, Vol. 92 No. 7, 2005, pp. 375-383.

[15] CH. LEE, "Multiple-Mode OTA-C Universal Biquad Filters", Circuits, Systems and Signal Processing April 2010, Vol. 29, No. 2, pp. 263-274.
[16] D. R. DINESH PRASAD, A. K. S. BHASKAR, "Universal current-mode biquad filter using dual output current differencing transconductance amplifier", AEU - International Journal of Electronics and Communications, Vol. 63, No. 6, Jun. 2009, pp. 497501.

[17] WORAPONG TANGSRIRAT, TATTAYA PUKKALANUN, "Structural generation of two integrator loop filters using CDTAs and grounded capacitors", International Journal of Circuit Theory and Applications, Vol. 39, No. 1, Jan. 2011, pp. 31-45.

[18] C. M. CHANG, B. M. AL-HASHIMI, C. L. WANG, C. W. HUNG, "Single fully differential current conveyor biquad filters", In Proc. IEE Circuits, Devices and Systems, Vol. 150, No.: 5 Oct. 2003, pp. 394-398

[19] F. KACAR, B. METIN, H. KUNTAM, O. CICEKOGLU, "Current-Mode Multifunction Filters Using a Single FDCCII", In Proc. International Conference Electrical and Electronics Engineering (ELECO), Nov. 2009, pp. II-54 - II-57.

[20] H. CHEN', S. WANG, P. LI, NIEN-HSIEN CHOU', CHIH-HAO CHANG, "Single FDCCII-based current-mode universal biquadratic filter", In Proc. The 2nd International Conference Consumer Electronics, Communications and Networks (CECNet),Yichang, China, Apr. 2012, pp. 2076 - 2079.

[21] J. JERABEK, K. VRBA, "A Controllable Universal Filter Using Multi-Output Current Followers" (Řiditelný univerzální filtr s vícevýstupovými proudovými sledovači), Elektrorevue - Interne Journal (http://www.elektrorevue.cz), No. 35, 2008, pp. 35-1 - 35-10.

[22] R. SENANI, S. S. GUPTA, "Current-Mode Universal Biquad Using Current Followers: A Minimal Realization", Radioengineering, Vol. 20 No. 4, Dec. 2011, pp. 898-904.

[23] A. Ü. KESKIN, E. HANCIOGLU, "Current mode multifunction filter using two CDBAs", AEU - International Journal of Electronics and Communications Vol. 59, No. 8, 2005, pp. 495-498.

[24] T. TSUKUTANI, Y. SUMI, N. YABUKI, "Electronically tunable current-mode universal biquadratic filter using CCCDBAs", In Proc. International Symposium Intelligent Signal Processing and Communications Systems ISPACS, Bangkok, Thailand, 2008, pp. 1 - 4

[25] J. KOTON, N. HERENCSAR, K. VRBA, J. JERABEK, "Digitally Adjustable Current Amplifier and its Application in Fully Differential Current-Mode Band- Pass Filter Design", Elektrorevue - Internet Journal (http://www.elektrorevue.cz), No. 90, 2010, pp. 47-52.

[26] J. JERABEK, K. VRBA, "Comparison of the Fully-Differential and Single-Ended Solutions of the Frequency Filter with Current Followers and Adjustable Current Amplifier", In Proc. ICN2012 The Eleventh International Conference on Networks. Reunion, France: IARIA, 2012, pp. 50-54.

[27] K. VRBA, J. JERABEK, "Filters Based on Active Elements with Current Mirrors and Inverters", International Transactions Communication and Signal Processing, Vol. 1, No. 8, 2006.

[28] R. SPONAR, K. VRBA, "Measurements and Behavioral Modelling of Modern Conveyors", International Journal of Computer Science and Network Security, Vol. 3A, No. 6, 2006, pp. 57-63

[29] K. VRBA, J. JERABEK, "Selected Features of The Universal Current Conveyor - application illustration" (Vybrané vlastnosti universálního proudového konvejoru - ukázka návrhu aplikace), Elektrorevue Internet Journal (http://www.elektrorevue.cz), No. 33, 2006, pp. 1-9.

[30] J. KOTON, N. HERENCSAR, K. VRBA, I. KOUDAR, "Fully differential current-mode filters using digitally adjustable current amplifier", Elektrorevue - Internet Journal (http://www.elektrorevue.cz), No. 45, pp. 45-1-45-4.

[31] J. JERABEK, R. ŠOTNER, K. VRBA, I. KOUDAR, "A Fully Differential universal tunable filter with current active elements", (Plně diferenční univerzální a řiditelný filtr s proudovými aktivními prvky) Elektrorevue - Internet Journal (http://www.elektrorevue.cz), No. 7 , 2010, pp. 7-1 - 7-6

[32] J. JERABEK, K. VRBA, "The Proposal of Frequency Filters With Current Active Elements Based on Integrators", (Návrh kmitočtových filtrů pomocí integračních článků s proudovými aktivními prvky) Elektrorevue - Internet Journal (http://www.elektrorevue.cz), No. 9 2009, pp. 9-1 - 9-7. 